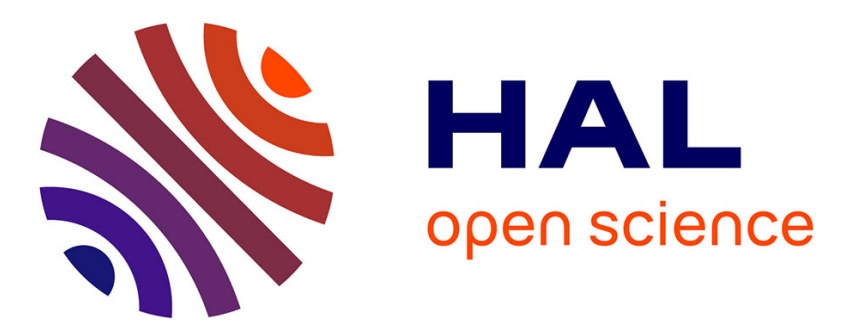

\title{
Voltage-dependent anion channel 1 and 2 are expressed in porcine oocytes
}

\author{
María Carolina Cassará, Viviana Andrea Menzel, Klaus-Dieter Hinsch, \\ Christine Wrenzycki, Elvira Hinsch
}

\section{- To cite this version:}

María Carolina Cassará, Viviana Andrea Menzel, Klaus-Dieter Hinsch, Christine Wrenzycki, Elvira Hinsch. Voltage-dependent anion channel 1 and 2 are expressed in porcine oocytes. Bioscience Reports, 2009, 30 (3), pp.193-200. 10.1042/BSR20090088 . hal-00479317

\section{HAL Id: hal-00479317 https://hal.science/hal-00479317}

Submitted on 30 Apr 2010

HAL is a multi-disciplinary open access archive for the deposit and dissemination of scientific research documents, whether they are published or not. The documents may come from teaching and research institutions in France or abroad, or from public or private research centers.
L'archive ouverte pluridisciplinaire HAL, est destinée au dépôt et à la diffusion de documents scientifiques de niveau recherche, publiés ou non, émanant des établissements d'enseignement et de recherche français ou étrangers, des laboratoires publics ou privés. 
Short running title: VDAC1 and 2 from oocytes

Voltage-dependent anion channel 1 and 2 are expressed in porcine oocytes

María Carolina Cassará ${ }^{\text {a,* }}$, Viviana Andrea Menzel ${ }^{\mathrm{a}}$, Klaus-Dieter Hinsch ${ }^{\mathrm{b}}$, Christine Wrenzycki ${ }^{\mathrm{c}}$ Elvira Hinsch ${ }^{\mathrm{d}}$

a Center of Dermatology and Andrology, Justus Liebig University of Giessen, Gaffkystr. 14, D-35392 Giessen, Germany

b Borkum Riff Rehabilitation Clinic of the federal insurance for salaried employees' Institution (DRV-Bund), 26757 Borkum, Germany

${ }^{\mathrm{c}}$ University of Veterinary Medicine Hannover, Clinic for Cattle, Reproductive Medicine Unit, Bischofsholer Damm 15, 30173 Hannover, Germany

${ }^{\mathrm{d}}$ Department of Urology and Pediatric Urology, Justus Liebig University of Giessen, Rudolf-Buchheim-Str. 7, Germany

* Corresponding author. Tel: +49-641-9943-396; fax +49-641-9943-369

E-mail address: carolina.cassara@ yahoo.com (M.C. Cassará) 


\begin{abstract}
The eukaryotic voltage-dependent anion channel (VDAC) is a pore-forming protein originally discovered in the outer membrane of mitochondria. It has been established as a key player in mitochondrial metabolite and ion signaling. In addition, in recent years, it has also been proposed that VDAC is present in extra-mitochondrial membranes, and it has been related to cytoskeletal structures. However, little is known about the presence and intracellular localization of VDAC subtypes in mammalian gametes.

In this study we confirm the synthesis of VDAC1 and 2 subtypes in germinal vesicle (GV) and meiosis II (MII) stage porcine oocytes as well as their protein expression. A shift in the abundance of immunoreactive $32 \mathrm{kDa}$ VDAC protein between GV and MII stage oocytes was observed with anti-VDAC2 antibody. Furthermore, subcellular localization by confocal laser microscopy demonstrated fluorescent labeling of VDAC1 over the entire oocyte surface, suggesting the presence of VDAC1 in the porcine oocyte plasma membrane and around the cortical area. Anti-VDAC2 immunostaining yielded ring-like clusters of structures distributed on the cortical area in some GV but not in MII stage oocytes. These results are the first data obtained for VDAC in mammalian female gametes and provide the basis for studying protein-protein interactions, distribution and possible functions of VDAC subtypes during maturation and fertilization of mammalian oocytes.
\end{abstract}

Key words immunoblotting, indirect immunofluorescence, oocyte, RT-PCR, voltage-dependent anion channel 


\section{Introduction}

Voltage-dependent anion channels (VDAC) are a widespread class of pore-forming proteins $(30-35 \mathrm{kDa})$ mainly found in the outer mitochondrial membranes in most eukaryotic organisms (for reviews see [1,2] ). In addition to mitochondrial localization, in the past few years several reports demonstrated the presence of VDAC in the plasma membrane and caveolae-like domains, sarcoplasmic/endoplasmic reticulum, nuclear envelope and endosomes (for reviews see [3,4]).

VDAC have conserved sequences, and three different VDAC genes encoding distinctly expressed isoforms are known to exist in vertebrates [4,5]. Little is known in mammals about tissue-specific distribution, intracellular localization and the specific role of each isoform [5-7]. The existing information derives mainly from recombinant proteins expressed in model organisms like yeast or mutant mice [5,8-10]. This paucity of information is due to the fact that to date mainly VDAC1 has been purified and characterized from different animal tissues, in contrast to VDAC2 which was until now only obtained from bovine spermatozoa [11].

The basic, known function of VDAC is to form a diffusion pore with highly conserved characteristics in the outer mitochondrial membrane (OMM). The OMM functions as a link between mitochondrial metabolism and the rest of the cell. The involvement of VDAC in metabolic pathways and interactions with other supramolecular structures has been investigated $[2,4]$. VDAC has been implicated to play a significant role in the programmed cell death pathway (for review see [12]). Other recent roles attributed to VDAC were the participation in calcium trafficking in the cell and the interaction with cytoskeletal proteins [4,13-15].

Currently, there is only scant information regarding the expression and the function of VDAC proteins in gametes. In a previous study we reported the presence of VDAC in the outer dense fibers (ODF) of the bovine sperm flagellum [16] and their involvement in the regulation of essential sperm functions [17]. Furthermore, we have obtained and characterized highly enriched VDAC2 from bovine spermatozoa [11].

Steinacker et al. (2000) reported the localization of VDAC in the plasma membrane of Xenopus laevis oocytes [18]. The expression and subcellular distributions of Porin 1 and 2 (VDAC1 and 2) were also reported in ovaries of Drosophila melanogaster [19,20]. Wang et al., also identified VDAC1 and 2 in two- dimensional electrophoresis analysis of human ovary [21] relating it with a possible role in the atresia of follicles.

At present there is no evidence regarding the presence and the function of VDAC in mammalian oocytes. This work provides the first report of the expression and localization of endogenous VDAC in immature and mature porcine oocytes as well as the purification of VDAC2 from porcine oocytes.

\section{Materials and methods}

2.1. Collection of oocytes and in vitro maturation Ovaries of pre-pubertal gilts were transported at $37^{\circ} \mathrm{C}$ from a local abattoir in physiological saline solution containing 100 $\mathrm{mg} / \mathrm{ml}$ Kanamycin. Cumulus-oocyte complexes were aspirated from non-atretic follicles (3-6 mm diameter) and only oocytes with evenly granulated cytoplasm and several layers of cumulus cells were selected. The in vitro maturation was performed following the method described by Romar [22]. For all experiments, granulosa cell-free immature oocytes (germinal vesicle, GV) and mature oocytes (meiosis II, MII) were used. 
2.2. $\boldsymbol{R}$ T-PCR The total cellular RNA extracted from 10 porcine oocytes using an RNeasy mini-kit (Qiagen, Hilden, Germany) was reversibly transcribed into the firststrand cDNA through Omniscript Reverse Transcriptase (Qiagen). The subsequent amplification of the desired genes was performed using Taq DNA polymerase (Eppendorf, Hamburg, Germany) according to the manufacturer's protocol. The primer sequences derived from porcine cDNA sequences (GenBank) were constructed as follows for: $V D A C 1$, (5'-CAAAATCTGAGAATGGACTGGAA-3' and 5'TTGGTGAGAAGGATGAATCAAAG-3') and for $V D A C 2$, AAATCAAAGCTGACAAGGAA-3' and 5'-GACTTTTGCAGAAATGGAAG-3'). As a control for amplification 5'and 3'primers for the GAPDH gene were used $\left(5^{\prime}\right.$ CCAGAAGACTGTGGATGGCC-3' and 5'-CTGACGCCTGCTTCACCACC-3'). The amplification was conducted for 35 cycles at $94{ }^{\circ} \mathrm{C}$ for $45 \mathrm{~s}$, annealing temperature $(57$ ${ }^{\circ} \mathrm{C}$ ) for $45 \mathrm{~s}$, and $72{ }^{\circ} \mathrm{C}$ for $90 \mathrm{~s}$ with a final step of $72{ }^{\circ} \mathrm{C}$ for $5 \mathrm{~min}$.

2.3. Protein detection by immunoblotting Oocytes were incubated at $70{ }^{\circ} \mathrm{C}$ in a minimum volume of $0.9 \% \mathrm{NaCl}$ for $1 \mathrm{~h}$, then dissolved $1: 1(\mathrm{v} / \mathrm{v})$ in oocyte sample buffer (5\% SDS; $100 \mathrm{mM}$ Tris-HCl, pH 7; 25 mM EDTA; 12\% glycerol; 2\% bromophenol blue; $10 \% \beta$-mercaptoethanol) and vortexed for 5 min followed by a last heating step at $95{ }^{\circ} \mathrm{C}$. SDS-PAGE was performed according to Laemmli [23] in 12\% $(\mathrm{v} / \mathrm{v})$ polyacrylamide gels loaded with an extract from 300 oocytes per lane.

Proteins were subjected to immunoblotting following a published protocol [24]. The antibodies used were AS P1/6 (anti-VDAC1), monoclonal anti-human type I porin (P31HL, Calbiochem, Darmstadt, Germany) and AS P2/45 (anti-VDAC2) at appropriate dilutions. Characterization and specificity of the antibodies has been previously described [16].

2.4. Purification and protein identification by mass spectrometry of oocyte VDAC Protein samples were prepared from immature oocytes (3300 cells) solubilized in Triton X-100 extraction buffer (2\% v/v Triton X-100; $150 \mathrm{mM} \mathrm{NaCl} ; 50 \mathrm{mM}$ Tris-HCl, $\mathrm{pH}$ 7.4; $2 \mathrm{mM}$ DTT; $1 \mathrm{mM}$ EDTA; $10 \mathrm{mM}$ benzamidine; $0.2 \mathrm{mM}$ PMSF). The suspension was incubated for $90 \mathrm{~min}$ at $4{ }^{\circ} \mathrm{C}$ and finally centrifuged at $13800 \mathrm{xg}$ for $45 \mathrm{~min}$. The supernatant (extract A) was stored at $-80{ }^{\circ} \mathrm{C}$ until use. The remaining sediment was subjected to a second solubilization treatment as described above (extract B). The proteins from extract $A$ and $B$ were diluted 1:1 with $2 \%$ Triton X-100 extraction buffer. Each extract was applied to a dry hydroxyapatite-celite $(2: 1 \mathrm{w} / \mathrm{w})$ column [25]. The first two $\mathrm{ml}$ of the pass-through (VDAC-containing fraction) were collected separately in 1 $\mathrm{ml}$ fractions and stored at $-20{ }^{\circ} \mathrm{C}$ until use. Both extracts were subjected to semipreparative SDS-PAGE (12\% separating polyacrylamide gels) according to Laemmli [23] and proteins were visualized by staining with SilverQuest (Invitrogen, Karlsruhe, Germany). Protein bands were excised and subsequently subjected to MALDI-TOF mass spectrometry analysis (ChromaTec, Greifswald, Germany). Peptide mass fingerprinting database searching was carried out using available online software (http://www.matrixscience.com/).

2.5. Immunocytochemical localization of VDAC proteins For immunofluorescence microscopy, porcine oocytes were fixed in $3.7 \%$ (w/v) paraformaldehyde (Sigma, Munich, Germany) in phosphate-buffered-saline (PBS, $120 \mathrm{mM} \mathrm{NaCl}, 4 \mathrm{mM} \mathrm{KH} \mathrm{PO}_{4}$, $10 \mathrm{mM} \mathrm{Na} 2 \mathrm{HPO}_{4}, \mathrm{pH} \mathrm{7.4)}$ ) for $30 \mathrm{~min}$ at room temperature, washed three times for $5 \mathrm{~min}$ 
in PBS drops and blocked for $1 \mathrm{~h}$ with PBS supplemented with $1 \%$ skimmed milk powder (EuroClone, Milano, Italy; MP-PBS). Incubation with primary antibody P31HL (anti-VDAC1, Calbiochem), AS P1/6 (anti-VDAC1) and anti-VDAC2 antibody (Santa Cruz, Heidelberg, Germany) was performed for $60 \mathrm{~min}$ followed by three washes in $0.1 \%$ MP-PBS. Secondary FITC-conjugated antibodies were applied for $30 \mathrm{~min}$ : antimouse IgG (Sigma) for P31HL antibodies; anti-rabbit IgG (Sigma) for AS P1/6; and anti-goat IgG (Santa Cruz) for anti-VDAC2 antibodies. During the last $5 \mathrm{~min}$ of incubation, propidium iodide ( $100 \mu \mathrm{g} / \mathrm{ml}$, Sigma) was added to detect maturation stages. Finally, labeled oocytes were mounted onto slides, examined and recorded using a laser scanning confocal microscope (LSM 510, Zeiss Axioplan imaging, Gottingen, Germany). The microscope was equipped with an Argon and $\mathrm{HNe} 1$ laser.

For the assessment of intracellular localization of VDAC in immature oocytes, the paraformaldhyde-fixed cells were permeabilized for $5 \mathrm{~min}$ in $0.1 \%(\mathrm{v} / \mathrm{v})$ Triton X-100 (Serva, Heidelberg, Germany) in PBS. The antibodies used were monoclonal antihuman type I porin, P31HL (Calbiochem), AS P1/6 (anti-VDAC1), AS P2/45 (antiVDAC2) and anti-VDAC2 antibody (Santa Cruz) at appropriate dilutions.

\section{Results}

3.1. $\boldsymbol{R} \boldsymbol{T}-\boldsymbol{P C R}$ RT-PCR revealed that VDAC1 and VDAC2 mRNAs were expressed in porcine oocytes (Figure 1). Amplification of the coding sequences was detected in GV (VDAC1 lane A, VDAC2 lane B) and MII (VDAC1 lane C, VDAC2 lane D) stage oocytes. The primer pairs generated amplicons of $219 \mathrm{bp}$ (VDAC1) and $231 \mathrm{bp}$ (VDAC2) and the positive control GAPDH showed an amplification product of $248 \mathrm{bp}$ in GV and MII (GAPDH, lane A-D). All amplicons were sequenced on both strands (MWG Biotech, Ebersberg, Germany) and confirmed by blasting.

3.2. Protein detection by immunoblotting Figure 2 shows immunoblot results using protein extracts obtained from $300 \mathrm{GV}$ and 300 MII stage oocytes. VDAC proteins detected with the antiserum P1/6 (anti-VDAC1, lanes 1 and 2) and AS P2/45 (antiVDAC2, lanes 3 and 4) demonstrate the presence of the two VDAC isoforms, VDAC1 and VDAC2, in GV and MII oocyte protein extractions. A strong immunoreaction at the approximate molecular weight of $32 \mathrm{kDa}$ was visible in GV (lane 1) and MII oocytes (lane 2) using anti-VDAC1 antibodies. In contrast, anti-VDAC2 immunodetection presented a different staining pattern between immature and mature oocytes. In immature cells a polypeptide band of approximately $30 \mathrm{kDa}$ was observed; however, a faint immune reaction with a 50-55 $\mathrm{kDa}$ peptide was also visible (lane 3 ). In mature oocytes a single, strong immune reaction was observed at the molecular mass range of $50-55 \mathrm{kDa}$ (lane 4), while the $30 \mathrm{kDa}$ immunoreactive protein band was missing. In control experiments with the respective pre-immune sera, no immunoreactions were noticed (data not shown).

3.3. Purification and protein identification by mass spectrometry of oocyte VDAC The purification procedure of porcine oocyte VDAC was adapted from the method described for mammalian VDAC protein [25]. Proteins from immature porcine oocytes $(n=3300)$ were isolated by a two-step sequential extraction (extract A and B) as described in Material and Methods. 
In extract A, no VDAC protein was detected (data not shown). Extract B contained a single faint protein band of $30-32 \mathrm{kDa}$ in the first fraction (data not shown), while a higher amount was found in the second fraction (Figure 3). The protein band from fraction 2 was excised from the gel and subjected to MALDI-TOF MS followed by PMF analyses. The number of peptides matched covered $31 \%$ of the VDAC2 (Sus scrofa) protein.

3.4. Immunocytochemical localization of VDAC proteins in porcine oocytes In Figure 4 (A-C), GV stage non-permeabilized oocytes were prepared and assayed with antiVDAC antibodies. Anti-VDAC1 antiserum, AS P1/6, and monoclonal anti-human type 1 VDAC antibodies, P31HL (Calbiochem), yielded a dense dot-like arrangement of fluorescent labeling primarily confined to the oocyte surface (Figure 4, A and B). For the polyclonal antibody AS P1/6, additional staining of the zona pellucida was observed (Figure 4 A, arrow). No distinct labeling of the oocyte surface was observed in control oocytes, which were treated only with the second antibody and the respective preimmune serum or $\mathrm{IgG}_{2 \mathrm{a}}$ (Figure 4, C). VDAC2 antibodies (Santa Cruz) displayed no fluorescent labeling; however, some cells exhibited signs of lesions and disturbance of cell integrity (data not shown).

For the assessment of intracellular VDAC polypeptides, membrane-permeabilized oocytes (GV and MII stage) were probed with anti-VDAC antibodies. Oocytes were completely scanned and photographed in three planes; however, mainly the equatorial plane data was included since it gave the most descriptive information.

As shown in Figure 4 for GV stage oocytes (D), the antiserum against VDAC1, AS P1/6 (D), presented a dense immunofluorescence labeling around the cortical area of the oocyte. Identical results were observed when immature oocytes were probed with another anti-VDAC1 antibody, P31HL (Calbiochem, data not shown). The assessment of MII porcine oocytes with both anti-VDAC1 antibodies yielded the same immunofluorescence pattern that has been observed in GV stage porcine oocytes (data not shown).

By using anti-VDAC2 antibodies from Santa Cruz, immunolabeling was observed in most of the GV oocytes tested (Figure 4, E). In these immunofluorescence-positive cells, variable spherical clusters, not evenly distributed throughout the cortical area, were detected (details observed in the oocyte cortical area of Figure 4, F). However, when porcine MII oocytes were tested with anti-VDAC2 antibodies from Santa Cruz, no specific reaction was observed (data not shown). The anti-VDAC2 antibody (AS P2/45) displayed no specific fluorescence labeling in immature and mature porcine oocytes (data not shown).

\section{Discussion}

In previous studies, we reported the expression, localization and functional characterization of VDAC isoforms in bovine testis and spermatozoa [11,16,26]. Furthermore, we presented new results that indicate the participation of VDAC proteins in essential sperm functions [17]. In relation VDAC in mammal oocytes have not yet been investigated.

Using RT-PCR, we demonstrated for the first time the expression of VDAC1 and VDAC2 within immature $(\mathrm{GV})$ and in vitro-matured (MII) porcine oocytes. The amplification products detected in porcine oocytes corresponded to the published coding sequence. The presence of additional sequences corresponding to an unspliced variant, 
as has been described previously for Porin 2 (VDAC2) in Drosophila melanogaster, remains to be elucidated [19].

Specific antibodies generated against VDAC1 and VDAC2 allowed investigation of the expression pattern of VDAC proteins in oocytes. Immunoblot analyses demonstrated the expression of VDAC1 in GV and MII maturation stages. Testing of immature porcine oocytes with anti-VDAC2 antibodies yielded VDAC2 protein having the same molecular weight range of about $30-32 \mathrm{kDa}$ as has been reported for sperm VDAC2 [16]. Additionally, we noticed a faint immunoreactive band with a higher molecular weight of approximately $50-55 \mathrm{kDa}$. Interestingly, in mature oocytes (MII) only a single, strong immunoreaction with anti-VDAC2 antibodies was observed with the 50$55 \mathrm{kDa}$ protein band while the original immunoreactive $30-32 \mathrm{kDa}$ VDAC protein disappeared. This result enhances the hypothesis of the expression of two VDAC2 subisoforms, with different polypeptide lengths, and with a pattern of similar posttranslational modifications [11]. Guarino et al. (2006) suggested that a high molecular weight VDAC protein in drosophila ovaries could be the product of mRNA still containing intron sequences.

We sought to further investigate the identity of the immunoreactive protein bands by purifying porcine oocyte VDAC proteins to apparent homogeneity and subsequent sequencing of the polypeptides using hydroxyapatite/celite purification [25] and MALDI TOF MS analyses, respectively. To obtain sufficient material for sequencing, high amounts of granulosa cell-free oocytes and a two-step protein extraction were necessary. Here we report, to our knowledge for the first time, the purification of the 30$32 \mathrm{kDa}$ VDAC2 protein from mammalian immature oocytes.

The VDAC1 and the VDAC2 immuno-related 50-55 kDa polypeptide, identified by immunological methods in immature porcine oocytes, could not be detected in the VDAC protein-containing hydroxyapatite/celite throughput. Presumably, the amount of these proteins was too low or the proteins were retained in the hydroxyapatite/celite column [27].

Having identified VDAC proteins in mature and immature porcine oocytes, the subcellular distribution of these proteins was studied. The cytochemical analyses of nonpermeabilized oocytes with anti-VDAC1 antibodies could reveal the presence of VDAC1 in the plasma membrane region. Very similar staining patterns were obtained with the two different anti-VDAC1 antibodies. However, AS P1/6 (antiserum), additionally displayed immunofluorescence of the zona pellucida. Compared with the specific staining pattern of the monoclonal anti-VDAC1 antibody P31HL (Calbiochem), this observation most probably is due to nonspecific binding to this extracellular oocyte matrix.

The fluorescence pattern of anti-VDAC1 antibodies is reminiscent of the cytological staining observed in Xenopus laevis oocytes [18]. Furthermore, the dot-wise labeling pattern at the cell surface suggests a plasma membrane localization of VDAC1. Because the oocytes assayed in our study were not permeabilized, we assume that the VDAC1 epitopes detected by the two antibodies are localized at the extracellular plasma membrane domain of the oocyte. The first evidence for an extra-mitochondrial localization of VDAC protein in the plasma membrane of human B lymphocytes was published in 1989 [28]. Several reports on the presence of VDAC as an integral membrane protein of various kinds of cells and organelles supported this study [2,3,2931]. Our results confirm the localization of VDAC1 in the plasma membrane of porcine oocytes; however, no information on the function of plasma membrane-bound VDAC1 
in oocytes is yet available. Several studies suggest that VDAC in the plasma membrane of somatic cell types act as anion channels involved in volume regulatory mechanisms $[32,33]$. The participation of VDAC1 in the volume regulatory process of mammalian spermatozoa was reported recently for gametes [17]. VDAC2 was not observed in the oocyte plasma membrane, suggesting separate localizations and functions of both isoforms in the oocyte.

After having found that anti-VDAC 1 antibodies bind to the outer surface of the oocyte plasma membrane, we were interested to identify VDAC proteins in the ooplasm of immature and mature porcine oocytes. Using confocal microscopy, it was possible to detect VDAC1 and VDAC2 proteins in different localizations of the porcine ooplasm. VDAC1 was clearly observed at the cortical area of immature and mature oocytes. Thus, the distribution of VDAC1 proteins seemed to be stable throughout the meiotic maturation. In the literature, it has been reported that in the GV stage of mammalian oocytes, actin filaments are distributed as a relatively thick, uniform area around the cell cortex and are also found near the germinal vesicle. After germinal vesicle breakdown (GVBD), microfilaments are predominantly found at the cortex of the cell and around the female chromatin [34]. The interaction of VDAC with other cellular proteins, especially those of the cytoskeleton, has been reported in recent years [15,35]. G-actin has been demonstrated to modulate VDAC gating in Neurospora crassa [14], whereas in HeLa cells the dynein light chain Tctex1 was shown to regulate VDAC [13]. Furthermore, VDAC were identified as binding sites for microtubule-associated protein 2 (MAP2) in the outer membrane of rat brain mitochondria $[15,36]$. The localization of VDAC1 at the cortical area of the oocyte might indicate an interaction of VDAC1 with cytoskeleton proteins that are predominantly found in this area of the cell.

The observed pattern of VDAC1 distribution could also suggest a mitochondrial localization. The presence of VDAC protein on the outer membrane of mitochondria from eukaryotic cells is well established [37,38]. During porcine oocyte maturation, the distribution of oocyte mitochondria was reported in the perinuclear area in GV stage oocytes, and large mitochondrial foci form and relocate to the inner cytoplasm in mature oocytes [39]. In mouse oocytes, mitochondria are clustered at the periphery of the large nucleus and the cortical area, but they disperse through the cytoplasm during maturation. This pattern of distribution may be related to the high energy requirement in the cortex, as the oocyte requires the support of cumulus cells at this stage [39].

Staining patterns observed with anti-VDAC2 antibodies differed from that of the VDAC1 isoform. In immature porcine oocytes, VDAC2 antigen was detected as distinct but not evenly distributed spherical clusters throughout the cortical area of the ooplasm. Thus, it can be speculated that VDAC1 and VDAC2 are present in different intracellular compartments of the oocyte. Our results implicate that in oocytes VDAC subtypes might be involved in the regulation of different cell functions (e.g. cell maturation or apoptosis). However, the exact localization and role of VDAC in the regulation of particular oocyte functions remain to be investigated.

In mature oocytes, the labeling pattern of VDAC2 protein completely disappeared after in vitro maturation, apparently indicating an interrelation of VDAC2 distribution or integrity with the cell's developmental stage. Nevertheless, the lack of immunoreactivity observed in mature oocytes could be also explained with a posttranslational change of the conformation of VDAC2 protein that hinders binding of the antibody to the native protein. It has been shown previously that some of the oocyte organelles exhibit dramatic changes during meiotic progression. Although VDAC were 
originally thought to be only located in the OMM, several investigations reported the presence in other cell compartments, e.g. nuclear envelope, endosomes, sarcoplasmic/endoplasmic reticulum, caveolae and other organelles of somatic cells [3,4,40-42]. The distribution of caveolae in Caenorhabditis elegans oocytes [43] resembles that observed in our immunofluorescence studies with anti-VDAC2. However, preliminary double staining experiments, containing anti-VDAC2 and antiCaveolin 1 antibodies, showed only a partial overlapping of both proteins. More research is essential to determine VDAC localization in these or other organelles in mammalian oocytes.

Anti-VDAC2 antibodies clearly exhibited different labeling patterns within immature oocytes. In the future it will be of great interest to study if the difference observed in VDAC2 labeling is conditioned to individual characteristics of each oocyte (e.g. oocyte quality). The identification of quality markers for oocyte fertilization capacity would be of great help in clinical applications and in vitro production.

The data obtained for VDAC2 using immunofluorescence are in line with the immunoblot experiments performed in this study, where shifts of apparent molecular masses of VDAC antigens during maturation were detected. The immunoreactive band at 30-32 kDa was no longer found after oocyte maturation, and a strong immunoreaction was observed in the $50-55 \mathrm{kDa}$ molecular weight range. The $50-55 \mathrm{kDa}$ anti-VDAC antigen, which is evidently the only VDAC2-related protein in the ooplasm of mature oocytes, could possibly represent a homodimerization/oligomerization product of these integral membrane proteins [44-46] or a tight complex of VDAC with other polypeptides [35]. However, it is tempting to speculate that either alterations of intracellular distribution of VDAC2 or protein-protein interactions of VDAC isoforms are causally related to the shift of apparent molecular masses during the maturation of oocytes.

The identification and localization of VDAC isoforms in different compartments of maturing porcine oocytes unveiled in this study could be the basis for better understanding of the molecular mechanisms of oocyte functions as well as the basis for novel clues concerning the role of VDAC proteins in the regulation of physiological processes of cells.

\section{Acknowledgements}

The authors wish to thank the colleagues of the Institute for Animal Breeding Biotechnology at the Federal Agricultural Research Centre (FAL; Neustadt, Germany) for the excellent technical assistance and support.

This project was supported by funds from the Deutsche Forschungsgemeinschaft GRK 533. This publication includes parts of the thesis of M. C. Cassará. 


\section{Figures}

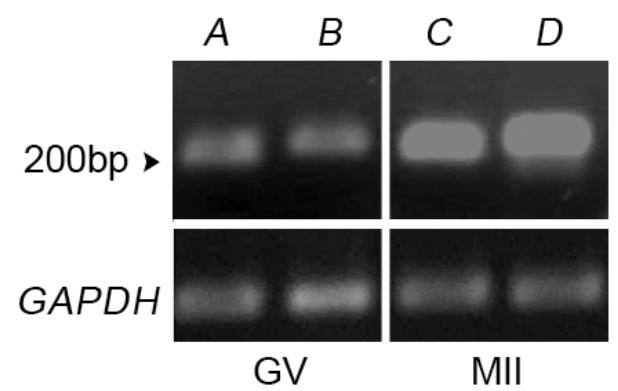

\section{Figure 1:}

RT-PCR of VDAC1 and VDAC2 isoform sequences in porcine mRNA obtained from GV and MII oocytes.

VDAC1 and VDAC2 gene expression in porcine oocytes. GV (lane A and B) and MII (lane $\mathrm{C}$ and $\mathrm{D}$ ) stage oocytes were assayed with specific primers. VDAC1 (lane A and C; 213bp), VDAC2 (lane B and D; 231bp) and GAPDH (lower panel, 248bp).

\section{Figure 2:}

\section{Immunoblotting of VDAC1 and VDAC2 from porcine oocytes}

Detection of VDAC isoforms in porcine GV (immature) and MII stage (mature) oocytes. Proteins of 300 oocytes per lane were separated by 12\% SDS-PAGE and transferred to nitrocellulose membranes. Membranes (lane 1 and 2) were incubated with anti-VDAC1 antibody (AS P1/6, 1:100). A second set of membranes (lane 3 and 4) were immunoprobed with anti-VDAC2 antibody (AS P2/45, 1:100). Bound antibodies were detected with protein A-HRP (1:3000) followed by detection with an ECL system. 


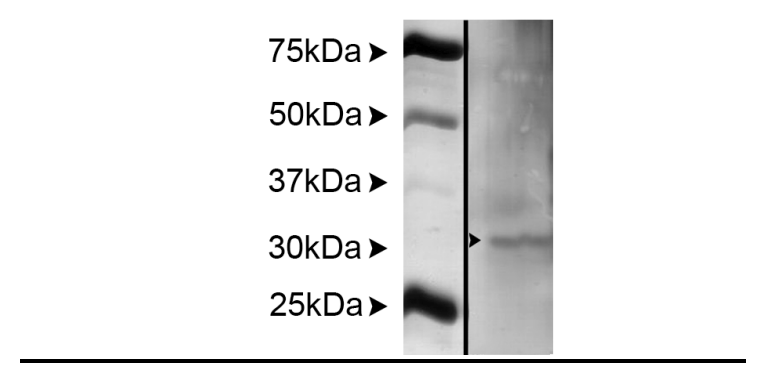

Figure 3:

Purification of VDAC2 protein from immature porcine oocytes

Protein extraction and hydroxyapatite-celite purification of $3300 \mathrm{GV}$ stage porcine oocytes. Protein fractions were separated in 12\% SDS-PAGE and silver stained. The second fraction obtained from extraction B yielded a single stained band (arrow). A Mascot MS/MS ion search identified the tagged band as VDAC2 (Sus scrofa).
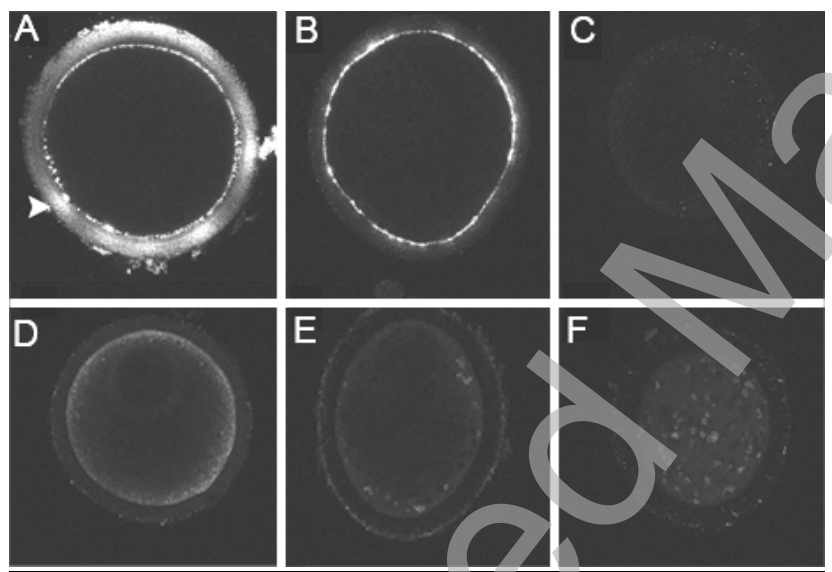

\section{Figure 4:}

\section{Immunolocalization of VDAC1 and VDAC2 protein in porcine oocytes}

Upper panel

Confocal laser microscopy images of immature porcine oocytes in the equatorial plane without a permeabilization step (A, B and C). Oocytes were incubated with antiVDAC1 antibodies. A: AS P1/6 (1:20) and B: P31HL (Calbiochem, 1:4), revealed by FITC-labeled anti-rabbit antibody (1:20) and anti-mouse antibody (1:8), respectively. C: Sample for negative control; oocyte exposed to $\operatorname{IgG}_{2 \mathrm{a}}$. Zona pellucida (A, arrow). Original magnification X 600 .

\section{Lower panel:}

Subcellular immunolocalization of VDAC protein isoforms in paraformaldehyde-fixed porcine immature stage oocytes (GV). Cells were treated with D: AS P1/6 (1:80), E and F: anti-VDAC2 (Santa Cruz; 1:5). A-E: Equatorial section of GV oocyte, F: Cortical plane of GV oocyte. Bound antibodies were detected with FITC-labeled second antibodies. Original magnifications X 600. 


\section{References}

1. Colombini, M. (1989) Voltage gating in the mitochondrial channel, VDAC. $J$. Membr. Biol. 111, 103-111

2. De Pinto, V., Messina, A., Accardi, R., Aiello, R., Guarino, F., Tomasello, M. F., Tommasino, M., Tasco, G., Casadio, R., Benz, R., De Giorgi, F., Ichas, F., Baker, M., and Lawen, A. (2003) New functions of an old protein: the eukaryotic porin or voltage dependent anion selective channel (VDAC). Ital. J. Biochem. 52, $17-24$

3. Bathori, G., Parolini, I., Szabo, I., Tombola, F., Messina, A., Oliva, M., Sargiacomo, M., De Pinto, V., and Zoratti, M. (2000) Extramitochondrial porin: facts and hypotheses. J. Bioenerg. Biomembr. 32, 79-89

4. Shoshan-Barmatz, V., Israelson, A., Brdiczka, D., and Sheu, S. S. (2006) The voltage-dependent anion channel (VDAC): function in intracellular signalling, cell life and cell death. Curr. Pharm. Des 12, 2249-2270

5. Sampson, M. J., Lovell, R. S., and Craigen, W. J. (1997) The murine voltagedependent anion channel gene family. Conserved structure and function. J. Biol. Chem. 272, 18966-18973

6. Messina, A., Oliva, M., Rosato, C., Huizing, M., Ruitenbeek, W., van den Heuvel, L. P., Forte, M., Rocchi, M., and De, P., V (1999) Mapping of the human Voltage-Dependent Anion Channel isoforms 1 and 2 reconsidered. Biochem. Biophys. Res Commun. 255, 707-710

7. Rahmani, Z., Maunoury, C., and Siddiqui, A. (1998) Isolation of a novel human voltage-dependent anion channel gene. Eur. J. Hum. Genet. 6, 337-340

8. Anflous, K. and Craigen, W. J. (2004) in Bacterial and eukaryotic porins. (Benz, R., ed) pp. 285-307, WILEY-VCH, Weinheim

9. Blachly-Dyson, E., Zambronicz, E. B., Yu, W. H., Adams, V., McCabe, E. R., Adelman, J., Colombini, M., and Forte, M. (1993) Cloning and functional expression in yeast of two human isoforms of the outer mitochondrial membrane channel, the voltage-dependent anion channel. J. Biol. Chem. 268, 1835-1841

10. Messina, A., Guarino, F. Oliva, M., van den Heuvel, L. P., Smeitink, J., and De, P., V (2000) Characterization of the human porin isoform 1 (HVDAC1) gene by amplification on the whole human genome: A tool for porin deficiency analysis. Biochem. Biophys. Res Commun. 270, 787-792

11. Menzel, V. A., Cassara, M. C., Benz, R., De, P., V, Messina, A., Cunsolo, V., Saletti, R., Hinsch, K. D., and Hinsch, E. (2008) Molecular and functional characterization of VDAC2 purified from mammal spermatozoa. Biosci. Rep. (epub ahead of print)

12. Kroemer, G., Galluzzi, L., and Brenner, C. (2007) Mitochondrial membrane permeabilization in cell death. Physiol Rev. 87, 99-163

13. Schwarzer, C., Barnikol-Watanabe, S., Thinnes, F. P., and Hilschmann, N. (2002) Voltage-dependent anion-selective channel (VDAC) interacts with the dynein light chain Tctex1 and the heat-shock protein PBP74. Int. J. Biochem. Cell Biol. 34, 1059-1070

14. Xu, X., Forbes, J. G., and Colombini, M. (2001) Actin modulates the gating of Neurospora crassa VDAC. J. Membr. Biol. 180, 73-81

15. Linden, M. and Karlsson, G. (1996) Identification of porin as a binding site for MAP2. Biochem. Biophys. Res Commun. 218, 833-836 
16. Hinsch, K. D., De Pinto, V., Aires, V. A., Schneider, X., Messina, A., and Hinsch, E. (2004) Voltage-dependent anion-selective channels VDAC2 and VDAC3 are abundant proteins in bovine outer dense fibers, a cytoskeletal component of the sperm flagellum. J. Biol. Chem. 279, 15281-15288

17. Triphan, X., Menzel, V. A., Petrunkina, A. M., Cassara, M. C., Wemheuer, W., Hinsch, K. D., and Hinsch, E. (2008) Localisation and function of voltagedependent anion channels (VDAC) in bovine spermatozoa. Pflugers Arch. 455, 677-686

18. Steinacker, P., Awni, L. A., Becker, S., Cole, T., Reymann, S., Hesse, D., Kratzin, H. D., Morris-Wortmann, C., Schwarzer, C., Thinnes, F. P., and Hilschmann, N. (2000) The plasma membrane of Xenopus laevis oocytes contains voltage-dependent anion-selective porin channels. Int. J. Biochem. Cell Biol. 32, 225-234

19. Guarino, F., Specchia, V., Zapparoli, G., Messina, A., Aiello, R., Bozzetti, M. P., and De, P., V (2006) Expression and localization in spermatozoa of the mitochondrial porin isoform 2 in Drosophila melanogaster. Biochem. Biophys. Res. Commun. 346, 665-670

20. Specchia, V., Guarino, F., Messina, A., Bozzetti, M. P., and De, P., V (2008) Porin isoform 2 has a different localization in Drosophila melanogaster ovaries than porin 1. J. Bioenerg. Biomembr. 40, 219-226

21. Wang, L., Zhu, Y. F., Guo, X. J., Huo, R., Ma, X., Lin, M., Zhou, Z. M., and Sha, J. H. (2005) A two-dimensional electrophoresis reference map of human ovary. $J$. Mol. Med. 83, 812-821

22. Romar, R., Coy, P., Gadea, J., and Rath, D. (2005) Effect of oviductal and cumulus cells on zona pellucida and cortical granules of porcine oocytes fertilized in vitro with epididymal spermatozoa. Anim Reprod. Sci. 85, 287-300

23. Laemmli, U. K. (1970) Cleavage of structural proteins during assembly of the head of bacteriophage T4. Nature 227, 680-685

24. Hinsch, E. and Hinsch, K. D. (1996) Generation of antisera against mouse and human synthetic ZP3 peptides. Andrologia 28 Suppl 1, 9-14

25. De Pinto, V., Prezioso, G., and Palmieri, F. (1987) A simple and rapid method for the purification of the mitochondrial porin from mammalian tissues. Biochim. Biophys. Acta 905, 499-502

26. Hinsch, K. D., Asmarinah, Hinsch, E., and Konrad, L. (2001) VDAC2 (porin-2) expression pattern and localization in the bovine testis. Biochim. Biophys. Acta 1518, 329-333

27. De Pinto, V., Benz, R., and Palmieri, F. (1989) Interaction of non-classical detergents with the mitochondrial porin. A new purification procedure and characterization of the pore-forming unit. Eur. J. Biochem. 183, 179-187

28. Thinnes, F. P., Gotz, H., Kayser, H., Benz, R., Schmidt, W. E., Kratzin, H. D., and Hilschmann, N. (1989) Identification of human porins. I. Purification of a porin from human B-lymphocytes (Porin 31HL) and the topochemical proof of its expression on the plasmalemma of the progenitor cell. Biol. Chem. Hoppe Seyler 370, 1253-1264

29. Dermietzel, R., Hwang, T. K., Buettner, R., Hofer, A., Dotzler, E., Kremer, M., Deutzmann, R., Thinnes, F. P., Fishman, G. I., and Spray, D. C. (1994) Cloning and in situ localization of a brain-derived porin that constitutes a large-conductance 
anion channel in astrocytic plasma membranes. Proc. Natl. Acad. Sci. U. S. A 91, 499-503

30. Reymann, S., Florke, H., Heiden, M., Jakob, C., Stadtmuller, U., Steinacker, P., Lalk, V. E., Pardowitz, I., and Thinnes, F. P. (1995) Further evidence for multitopological localization of mammalian porin (VDAC) in the plasmalemma forming part of a chloride channel complex affected in cystic fibrosis and encephalomyopathy. Biochem. Mol. Med. 54, 75-87

31. Junankar, P. R., Dulhunty, A. F., Curtis, S. M., Pace, S. M., and Thinnes, F. P. (1995) Porin-type 1 proteins in sarcoplasmic reticulum and plasmalemma of striated muscle fibres. J. Muscle Res Cell Motil. 16, 595-610

32. Thinnes, F. P., Hellmann, K. P., Hellmann, T., Merker, R., BrockhausPruchniewicz, U., Schwarzer, C., Walter, G., Gotz, H., and Hilschmann, N. (2000) Studies on human porin XXII: cell membrane integrated human porin channels are involved in regulatory volume decrease (RVD) of HeLa cells. Mol. Genet. Metab 69, 331-337

33. Okada, S. F., O'Neal, W. K., Huang, P., Nicholas, R. A., Ostrowski, L. E., Craigen, W. J., Lazarowski, E. R., and Boucher, R. C. (2004) Voltage-dependent anion channel-1 (VDAC-1) contributes to ATP release and cell volume regulation in murine cells. J. Gen. Physiol 124, 513-526

34. Wang, W. H., Abeydeera, L. R., Prather, R. S., and Day, B. N. (2000) Polymerization of nonfilamentous actin into microfilaments is an important process for porcine oocyte maturation and early embryo development. Biol. Reprod. 62, 1177-1183

35. Roman, I., Figys, J., Steurs, G., and Zizi, M. (2006) Direct measurement of VDAC-actin interaction by surface plasmon resonance. Biochim. Biophys. Acta 1758, 479-486

36. Leterrier, J. F., Rusakov, D. A., Nelson, B. D., and Linden, M. (1994) Interactions between brain mitochondria and cytoskeleton: evidence for specialized outer membrane domains involved in the association of cytoskeleton-associated proteins to mitochondria in situ and in vitro. Microsc Res Tech. 27, 233-261

37. Lemasters, J. J. and Holmuhamedov, E. (2006) Voltage-dependent anion channel (VDAC) as mitochondrial governator--thinking outside the box. Biochim. Biophys. Acta 1762, 181-190

38. Benz, R. (1990) Biophysical properties of porin pores from mitochondrial outer membrane of eukaryotic cells. Experientia 46, 131-137

39. Sun, Q. Y., Wu, G. M., Lai, L., Park, K. W., Cabot, R., Cheong, H. T., Day, B. N., Prather, R. S., and Schatten, H. (2001) Translocation of active mitochondria during pig oocyte maturation, fertilization and early embryo development in vitro. Reproduction. 122, 155-163

40. Lisanti, M. P., Scherer, P. E., Vidugiriene, J., Tang, Z., Hermanowski-Vosatka, A., Tu, Y. H., Cook, R. F., and Sargiacomo, M. (1994) Characterization of caveolin-rich membrane domains isolated from an endothelial-rich source: implications for human disease. J. Cell Biol. 126, 111-126

41. Shoshan-Barmatz, V., Hadad, N., Feng, W., Shafir, I., Orr, I., Varsanyi, M., and Heilmeyer, L. M. (1996) VDAC/porin is present in sarcoplasmic reticulum from skeletal muscle. FEBS Lett. 386, 205-210 
42. Shoshan-Barmatz, V. and Israelson, A. (2005) The voltage-dependent anion channel in endoplasmic/sarcoplasmic reticulum: characterization, modulation and possible function. J. Membr. Biol. 204, 57-66

43. Sato, K., Sato, M., Audhya, A., Oegema, K., Schweinsberg, P., and Grant, B. D. (2006) Dynamic regulation of caveolin-1 trafficking in the germ line and embryo of Caenorhabditis elegans. Mol. Biol. Cell 17, 3085-3094

44. Distler, A. M., Kerner, J., Peterman, S. M., and Hoppel, C. L. (2006) A targeted proteomic approach for the analysis of rat liver mitochondrial outer membrane proteins with extensive sequence coverage. Anal. Biochem. 356, 18-29

45. Linden, M., Gellerfors, P., and Nelson, B. D. (1982) Pore protein and the hexokinase-binding protein from the outer membrane of rat liver mitochondria are identical. FEBS Lett. 141, 189-192

46. Babel, D., Walter, G., Gotz, H., Thinnes, F. P., Jurgens, L., Konig, U., and Hilschmann, N. (1991) Studies on human porin. VI. Production and characterization of eight monoclonal mouse antibodies against the human VDAC "Porin 31HL" and their application for histotopological studies in human skeletal muscle. Biol. Chem. Hoppe Seyler 372, 1027-1034 